\title{
Reseña de Mardones Barrera (Ed.) (2016): Historia local de la psicología: discusiones teóricas, metodológicas y experiencias de investigación
}

\author{
Juan Humberto Villagran Sotomayor \\ Universidad Santo Tomas, Sede Los Ángeles, Chile
}



El estudio de la psicología en Chile y Latinoamérica verbaliza de forma patente el cómo la psicología se ha convertido en una de las disciplinas más importantes en el campo de las ciencias sociales (Pinto en Mardones, 2016). Conocer nuestra historia y trayectoria como disciplina se traduce en una comprensión consciente de nuestro "ahora", permitiendo la construcción y deconstrucción de acciones a seguir, así como trazar caminos hacia el futuro. Conocer la historia de la psicología nos permite entender nuestra disciplina en contexto: todo avance que se ha realizado responde a un momento con características socioculturales y políticas específicas, las cuales determinan, en parte, las ideas, teorías y programas de investigación desarrollados $u$ omitidos en cierta época (Laborda, Quezada y Cornejo, 2013). No deberíamos dar por sentado la existencia de la psicología como rama de investigación independiente. En su lugar,
Mardones Barrera, Rodolfo (2016).

Historia local de la psicología: discusiones teóricas, metodológicas y experiencias de investigación. Santiago de Chile: RIL

Editores.

ISBN: 978 956-01-0272-0 comprenderemos mucho mejor la disciplina si examinamos las condiciones históricas que permitieron la aparición de esta manera particular de comprender al sujeto y su contexto (Parker, 2010, p. 21).

El presente texto aquí develado: Historia local de la psicología: discusiones teóricas, metodológicas y experiencias de investigación, plantea el necesario dialogo entre la psicología y otras ciencias sociales, según Jorge Pinto, Premio Nacional de Historia. De esta forma, el presente texto recoge experiencias concretas que hablan de contextos específicos que narran vivencias e investigaciones en distintos puntos cardinales de Latinoamérica y Europa.

Es por ello que este necesario Libro busca de manera sencilla y practica sacar a la luz y argumentar la naturaleza social de los procesos 
que permiten, de forma directa, construir y reforzar una identidad de la disciplina, permitiendo reconocer las experiencias asociadas a los entornos más cercanos de las comunidades expuestas a la globalización (Mardones, 2016). Esta fundación metodológica que busca establecer trazos de una historia de la psicología local e iberoamericana, deviene, en el fondo, en estrategias que permiten a una sociedad -0 en este caso particular, a un grupo de personas - tener conocimiento de sí mismo, de manera que se converge en una idea fáctica de un sujeto-en-el mundo, representando su identidad y continuidad frente al tiempo y al pasado (Halbwachs, 1968).

El presente texto versa en develar aspectos importantes que han contribuido a potenciar la historia de la psicología en nuestro país e Iberoamérica. En Chile, la psicología y sus distintas vertientes o subdisciplinas han experimentado innumerables cambios; dando cuenta de una historia particular que es necesario develarla y analizar a lo largo de su creación como ciencia en nuestro país.

De esta forma, es necesario poner énfasis en la forma introductoria y versátil que el autor plantea como labor académica en distintas partes de Latinoamérica y cómo se ha patentado, en distintas organizaciones y asociaciones, la importancia de pesquisar la historia de la psicología como interés, tanto de la academia en Chile como en otras latitudes en Latinoamérica.

La concepción de historia local cobra validez en la forma de contribución a la historia de la psicología, que en este texto genera una tensión entre historia local y los megarelatos universales, dictados por los discursos de poder. Es aquí que la propuesta es abogar por una horizontalidad de saberes, es aquí donde - según el autor- este texto cobra relevancia dentro del área disciplinar de la historia de la psicología.

La estructura central del libro se divide en dos partes: Por un lado, la primera parte Discusiones teóricas y metodológicas para la construcción de historias locales de la psicología comprende de 4 capítulos que abordan la tensión emergente entre epistemologías y metodologías en la construcción del saber local y su relevancia en las ciencias sociales en la actualidad. La segunda parte, Experiencias de investigación en torno a historias locales de la psicología, comprende 9 capítulos que develan los aportes de distintos autores que convergen en experiencias concretas de investigación en historia de la psicología y sus aportes en la historia local.

La primera parte del libro comienza con un capitulo escrito por el editor, Rodolfo Mardones, quien prepara al lector en las tensiones básicas entre el conocimiento científico y lo local, dando énfasis en su explicación en las nociones entre territorios y espacios, y cómo esta matriz de conocimiento da lugar a un saber contextual del espacio y el tiempo vivido. De esta forma, el autor concatena este conocimiento y producción local como un espacio periférico y en tensión con los saberes europeizantes y céntricos, dando énfasis al conocimiento científico latinoamericano.

El segundo capítulo de esta primera parte, escrito por Jorge Castro-Tejerina de la Universidad Nacional de Educación a Distancia (España), nos plantea aquella tensión patente entre o local y lo universal en la construcción del hombre moderno, dando énfasis a la posibilidad de hablar de tradiciones locales aplicables a la disciplina que aporten a la historización de la psicología.

El tercer capítulo, aportado por Gonzalo Salas de la Universidad Católica del Maule (Chile), plantea aspectos importantes en cuanto a la epistemología y la metodología del tratamiento de la historia de la psicología con énfasis en lo local, de forma que el autor teje una escritura entre las tramas de lo local y el debate en hacer historia interna y externa.

El cuarto capítulo y ultimo de la primera parte del libro, del académico e historiador Hugo Klappenbach, de la Universidad de San Luis (Argentina), refiere en este apartado las distintas concepciones de historia local y su vinculación con la psicología, de esta forma el autor muestra la emergencia de las psicologías nativas o autóctonas. Así, el autor concluye en la necesidad de evidenciar un proyecto de pesquisar la historia de la psicología policéntrica en Argentina.

La segunda Parte del libro comienza con un capitulo escrito por Ana Jaco-Videla y Víctor Portavales de la Universidade do Estado Rio de Janeiro (Brasil), el cual refiere acerca de la medición psicológica en Brasil, haciendo notar una discusión en torno a la concepción de centro/periferia y la impronta relación con 
la psicología y su historia, dando énfasis en el debate de cómo se llevó a cabo la realización de test psicológicos en Brasil.

Por otro lado, el segundo capítulo, escrito por Rubén Ardila, perteneciente a la Universidad Nacional de Colombia, plantea un abordaje sucinto respecto al estudio del comportamiento en América latina, puntualizando su análisis en tres teóricos y académicos de Latinoamérica, haciendo énfasis en sus logros y aportes a la historia de la psicología en la región.

El tercer capítulo, escrito por Rubén Benedicto Salmerón de la Universitat Autònoma de Barcelona, explora las trazas de la biopolítica en la dictadura Franquista de España. En el capítulo hace énfasis en las transformaciones biopolíticas de la sociedad española, siguiendo al psiquiatra español Antonio Vallejo Nágera y sus estudios en los campos de concentración franquistas, así como también deja ver las investigaciones en biopsiquísmo, cuyos estudios dan cuenta de una presumida inferioridad mental por parte de las personas con pensamientos marxistas.

Por otro lado, el capítulo cuarto de esta sección, María Inés Winkler y Gabriel Abarca de la Universidad de Santiago (Chile), presenta al lector una radiografía del papel de las mujeres en el saber psi, dando cuenta de una investigación histórica que combina el protagonismo y la acción social con la discriminación y la invisibilidad.

Tomas Caycho Rodríguez, de la Universidad San Martin de Porres (Perú), presenta el capítulo cinco de este libro, el cual centra en su investigación sobre los aportes realizados por Hipolito Unanue, médico y naturalista Limeño, quien centra su estudio en la psicología del habitante de Lima, capital del Perú, en el siglo XVIII. De esta forma, esta investigación versa en develar a Unanue como uno de los principales difusores del pensamiento científico del Perú.

Por su parte, en el capítulo seis, Pablo Norambuena Cárdenas, de la Universidad de Santiago de Chile, plantea una investigación acerca de la psiquiatría intracomunitaria en un periodo anterior al golpe de estado en Chile en 1973, de forma que el investigador pone énfasis en la figura del psiquiatra Juan Marconi, quien, junto a otros profesionales de la psicología, aportaron en la construcción de una nueva praxis en la salud mental comunitaria en Chile.

Por otro lado, el capítulo siete, de José E. Garcia de la Universidad Católica de Asunción (Paraguay), presenta una investigación historiográfica respecto a la psicología en Asunción, construyendo una contextualización histórica que converge en la creación de la carrera de psicología, así como los procesos curriculares, una caracterización y dificultades en la investigación, dando énfasis en las condicionantes ambientales como procesos particulares en la investigación de la historia de la psicología.

En el capítulo ocho, Miguel Gallegos y Martina Berra de la Universidad Nacional del Rosario y Conicet (Argentina), presentan el desarrollo histórico de la psicología rosarina pionera en la Argentina, dando cuenta del devenir histórico de la psicología como institución y los procesos histórico-políticos que han influido como ciencia social en esta localidad.

El capítulo número nueve y último de esta segunda parte, de Walter Arias de la Universidad Católica San Pablo (Perú), presenta la historia de la psicología, dictada por universidades diversas en esta ciudad, y su influencia en los procesos de formación en la ciudad de Arequipa.

Esta sucinta descripción de los contenidos del libro, pretende materializar la importancia de la historia en la psicología y las ciencias sociales como fin de modelación de un discurso coherente, contextual e identitario que da sentido y razón a la formación e investigación en la historia de la psicología en Latinoamérica.

Se trata de un texto que se sumerge en lo que ha sido y lo que se está develando en la construcción discursiva de la disciplina psi y cómo esta influye en la materialidad social, con el fin de pesquisar y mostrar realidades desde distintas cartografías.

\section{Referencias}

Halbwachs, Maurice (1968). La memoria colectiva. Prensas Universitaria de Zaragoza. España.

Laborda, Mario A.; Quezada, Vanetza E. \& Cornejo, Marcela. (2013). Serie Historia de la Psicología en Chile. Psykhe, 22(1), 107-109.

http://dx.doi.org/10.7764/psykhe.22.1.632 
Parker, lan (2010). La psicología como ideología. Contra la disciplina. Madrid: Ed. Catarata.

Pinto, Jorge (2016). Prólogo. En Rodolfo Mardones (Ed.), Historia local de la psicología: discusiones teóricas, metodológicas y experiencias de investigación (pp. 15 -18). Santiago de Chile: RIL Editores.

\title{
JuAn Humberto VILLAgran SOtomayoR
}

Psicólogo. Magister (c) y Especialista en Psicología Social Comunitaria. Docente Adjunto Universidad Santo Tomas, Sede Los Ángeles, Chile.

\section{DIRECCIÓN DE CONTACTO}

\author{
villagransotomayorj@gmail.com
}

\section{FORMATO DE CITACIÓN}

Villagran Sotomayor, Juan Humberto (2017). Reseña de Mardones Barrera (Ed.) (2016): Historia local de la psicología: discusiones teóricas, metodológicas y experiencias de investigación. Quaderns de Psicologia, 19(3), 319-322. http://dx.doi.org/10.5565/rev/qpsicologia.1402 